\title{
The impacts of exercise on pediatric obesity
}

Ronald J. Headid III, MS, Song-Young Park, PhD

School of Health and Kinesiology, University of Nebraska at Omaha, Omaha, NE, USA

Over the last few decades, the rates of pediatric obesity have more than doubled regardless of sociodemographic categorization, and despite these rates plateauing in recent years there continues to be an increase in the severity of obesity in children and adolescents. This review will discuss the pediatric obesity mediated cardiovascular disease (CVD) risk factors such as attenuated levels of satiety and energy metabolism hormones, insulin resistance, vascular endothelial dysfunction, and arterial stiffness. Additionally, early intervention to combat pediatric obesity is critical as obesity has been suggested to track into adulthood, and these obese children and adolescents are at an increased risk of early mortality. Current suggested strategies to combat pediatric obesity are modifying diet, limiting sedentary behavior, and increasing physical activity. The effects of exercise intervention on metabolic hormones such as leptin and adiponectin, insulin sensitivity/resistance, and body fat in obese children and adolescents will be discussed along with the exercise modality, intensity, and duration. Specifically, this review will focus on the differential effects of aerobic exercise, resistance training, and combined exercise on the cardiovascular risks in pediatric obesity. This review outlines the evidence that exercise intervention is a beneficial therapeutic strategy to reduce the risk factors for CVD and the ideal exercise prescription to combat pediatric obesity should contain both muscle strengthening and aerobic components with an emphasis on fat mass reduction and long-term adherence.

Key words: Pediatric obesity, Cardiovascular disease, Metabolic disease, Exercise

\section{Key message}

Pediatric obesity contributes to the development of vascular dysfunction and metabolic and cardiovascular diseases which have all been shown to track into adulthood, increasing the risk of early mortality. Early exercise intervention is critical for combating obesity-related comorbidities and the optimal exercise prescription has yet to be well documented. Exercise prescriptions to combat pediatric obesity should incorporate both aerobic and muscle-strengthening exercises with an emphasis on long-term adherence.

\section{Introduction}

In 2013 approximately 2.1 billion individuals were considered overweight or obese which was defined as a body mass index (BMI) greater than $25 \mathrm{~kg} / \mathrm{m}^{2} .{ }^{1)}$ Over the last few decades the obesity rates in more than 70 countries have doubled, ${ }^{2,3)}$ while the rate of this increase in obesity is higher in children than in adults regardless of sociodemographic categorization. ${ }^{2)}$ Additionally, epidemiological data indicate that the proportion of children and adolescents with obesity appears to be plateauing in recent years but the rate of more severe obesity cases continues to rise. ${ }^{4,5)}$ Although the development of pediatric obesity is a multifaceted process that involves genetic, behavioral, and environmental influences, ${ }^{6,7}$ the lifestyle behaviors during childhood and adolescence might have the greatest influence on the development of obesity. ${ }^{8,9)}$

Obesity is characterized by an energy imbalance that is affected by lifestyle behaviors such as poor dietary habits ${ }^{10-13)}$ and inadequate physical activity time ${ }^{14)}$ which are both strongly associated with the development of obesity. More specifically, sedentary behaviors such as increased video gaming, television watching, and computer screen time ${ }^{15,16)}$ are highly associated with the development of obesity. ${ }^{17)}$ The development of obesity often influences the onset of several cardiovascular disease (CVD) risk factors. ${ }^{18)}$ Additionally, the relative risk for CVDs such as hypertension, stroke, and heart disease is 1.5- to 5.1times higher in obese children when compared to children with normal body composition. ${ }^{19)}$ Combating pediatric obesity is critical as there is a strong connection between pediatric obesity and adult obesity. ${ }^{4,20)}$ A previous meta-analysis identified that when compared to normal-weight children, obese children are 5 times more likely to be obese in adulthood, ${ }^{21)}$ and about $80 \%$ of obese adolescents remain obese in adulthood. ${ }^{22)}$

Physical inactivity and sedentary behaviors are significant contributors to the development of pediatric obesity. ${ }^{14,23,24)}$ Physical activity and exercise have been suggested as powerful treatments to help prevent obesity as well as improve obesityrelated risk factors in children and adolescents. ${ }^{25-27)}$ For every one hour of moderate-to-vigorous activity there is a $10 \%$ decrease in the risk of developing obesity. ${ }^{14)}$ Additionally, regular exercise is

Corresponding author: Song-Young Park, PhD. School of Health and Kinesiology, University of Nebraska at Omaha, 6001 Dodge St, Omaha, NE, USA 凶 Email: song-youngpark@unomaha.edu, https://orcid.org/0000-0001-7403-1334

Received: 2 June, 2020, Revised: 8 July, 2020, Accepted: 10 July, 2020

This is an open-access article distributed under the terms of the Creative Commons Attribution Non-Commercial License (http://creativecommons.org/licenses/by$\mathrm{nc} / 4.0 /$ ) which permits unrestricted non-commercial use, distribution, and reproduction in any medium, provided the original work is properly cited.

Copyright (c) 2021 by The Korean Pediatric Society 
considered an effective treatment for reducing inflammation, ${ }^{28)}$ obesity-related risk factors, and the development of comorbidities. ${ }^{29)}$ Therefore, this review will focus on the health risks associated with pediatric obesity and further discuss optimal exercise strategies, specifically, aerobic exercise (AE) such as running, cycling, or jump rope, resistance training (RT) such as free weights, cable machines, or resistance bands, and combined aerobic and resistance exercise (CRAE) such as the combination of running and free weights, to combat pediatric obesity and the associated risk factors and comorbidities (Table 1).

\section{Pediatric obesity}

The prevalence of pediatric obesity continues to increase around the world ${ }^{1)}$ and obesity is expected to affect 91 million children by the year 2025.2) Obesity is a multifactorial condition that can be affected by genetic, psychological, lifestyle, environmental, behavioral, and hormonal factors. ${ }^{3)}$ It is well-accepted that there is no single cause of pediatric obesity, however, obesity is characterized by the accumulation of excess fat mass which develops when caloric intake exceeds total energy expenditure. ${ }^{4)}$ The neuroendocrine regulation of fat stores is a complex system based on circulating hormones, which send signals to specialized neurons in the hypothalamus to indicate the status of body fat (BF) stores in the body, which in turn induces the appropriate response necessary to maintain these fat stores. ${ }^{5)}$ Amidst other important functions, the hypothalamus is the control center for feelings of hunger and satiety. An individual's susceptibility to the development of obesity can in part be explained by mechanisms that may negatively affect hypothalamic neurons, leading to an improper hunger/satiety balance, and genetic and environmental modulators such as leptin and insulin resistance (IR). ${ }^{5)}$ Both leptin resistance and IR are associated with feeding behavior and weight gain. Pediatric obesity also negatively effects cardiovascular health and is also accompanied by a host of other comorbidities and associated risk factors. ${ }^{8)}$

\section{Health risks associated with obesity}

Pediatric obesity is associated with a myriad of CVD risk factors including increased IR, ${ }^{9)}$ impaired glucose tolerance, dyslipidemia, ${ }^{10,11)}$ impaired microvascular function, ${ }^{12)}$ systemic low-grade inflammation, ${ }^{13)}$ increased artery wall thickness, ${ }^{14)}$ and elevated blood pressure (BP). ${ }^{97}$ In addition to an increased risk of $\mathrm{CVD}$, pediatric obesity is also associated with the development of nonalcoholic fatty liver disease, ${ }^{9)}$ cancer, pulmonary disease, asthma, sleep apnea, orthopedic problems, and depression ${ }^{15-17)}$ and has also been identified as an independent risk factor for the development of insulin-resistant type 2 diabetes (T2D). ${ }^{18-21)}$ Furthermore, the severity of these obesity-related risk factors and comorbidities significantly increases with the severity of obesity. ${ }^{17,18,22,23)}$ Combating obesity early in childhood is critical as even mild reductions in body mass before the onset of puberty has been shown to decrease the risk of CVD and other obesity- related risk factors such as hypertension, dyslipidemia, T2D, and coronary heart disease later in life if normal bodyweight is maintained. 22-25) If pediatric obesity cannot be treated appropriately, obese children and adolescents will be at an increased risk of premature death ${ }^{26}$ and a significantly increased risk for CVD and CVD-related mortality in adulthood. ${ }^{27)}$

\section{Pediatric obesity and health risks track into adulthood}

In 2015, there were approximately 4 million international obesity-related deaths with $70 \%$ of these deaths being attributed to CVD. ${ }^{28,29)}$ Pediatric obesity has been known as a significant contributor to the current obesity and CVD epidemics in adults. ${ }^{27)}$ Individuals who are obese during childhood are more likely to become obese as adults ${ }^{30-33)}$ and there is compelling evidence suggesting that obesity-associated CVD risk factors, such as dyslipidemia, IR, and elevated BP, track from childhood into adulthood. ${ }^{18,27,34,35)}$ Obese children who were tracked from childhood to adulthood were more likely to suffer from CVD, digestive disease, metabolic diseases, and cancer as an adult when compared to children of normal weight. ${ }^{8}{ }^{816}$ Additionally, obesity in childhood is strongly associated with a 3.5-times higher risk of CVD mortality in adulthood and is projected to account for as much as $25 \%$ of all adult CVD-related deaths. ${ }^{27)}$ The manifestation of obesity-related CVD risk factors can appear in as early as the third year of life, ${ }^{15,20)}$ and the duration of obesity during childhood and adolescence is associated with increased risk of developing obesity-related comorbidities and CVDrelated mortality in adulthood. ${ }^{18,19,23)}$ In fact, pediatric obesity is a well-established predictor of CVD and premature mortality in adulthood ${ }^{26,36,37)}$ thereby highlighting the importance of early intervention to prevent the development of obesity. These types of interventions should serve to target improvements in several metabolic, hormonal, and cardiovascular parameters to better protect young populations from future CVD complications, as well as instilling a healthy lifestyle that can be maintained throughout adulthood.

\section{Metabolic syndrome and adipokines}

Metabolic syndrome (MetS) is defined as a cluster of conditions including high central adiposity, dyslipidemia, and high fasting blood glucose, all of which contribute to an increased risk of CVD. ${ }^{30)}$ Obesity has been identified as a major contributor to the development of $\mathrm{Met}^{30)}$ and obesity-associated MetS risk factors have been shown to track from childhood into adulthood. ${ }^{31,32)}$ Obesity is characterized by an increase in adipose tissue which is considered an active metabolic endocrine organ and a source of inflammation through the production of inflammatory cytokines. ${ }^{33,34)}$ Adipose tissue-derived cytokines are referred to as, adipokines, and 2 of the most prominent adipokines are leptin and adiponectin which are negatively affected by obesity. 35,36) Additionally, T2D is the most common comorbidity associated with pediatric obesity. ${ }^{37)}$ T2D development, whether 
Table 1. Characteristics of exercise studies investigating the effects of exercise in pediatric obesity

\begin{tabular}{|c|c|c|c|c|c|c|c|}
\hline Study & Exercise modality & Intensity & Frequency & $\begin{array}{l}\text { Duration } \\
\text { (min) }\end{array}$ & $\begin{array}{l}\text { Total time } \\
\text { per week } \\
\text { (min) }\end{array}$ & $\begin{array}{l}\text { Intervention } \\
\text { duration } \\
\text { (wk) }\end{array}$ & Outcomes \\
\hline Karacabey $^{52)}$ & $\begin{array}{l}\text { Aerobic exercise } \\
\text { (walking/jogging) }\end{array}$ & Moderate & $3 x / w k$ & $25-55$ & $75-165$ & 12 & $\downarrow$ BMI, $\downarrow$ LDL, $\downarrow$ cortisol, $\downarrow$ leptin, $\downarrow$ insulin \\
\hline Lee et al. ${ }^{141)}$ & $\begin{array}{l}\text { Aerobic exercise } \\
\text { (jump rope) }\end{array}$ & Moderate & $4 x /$ wk & $40-50$ & $120-150$ & 12 & $\downarrow$ Plasma Visfatin, $\downarrow$ insulin resistance \\
\hline Kim et al. ${ }^{70)}$ & $\begin{array}{l}\text { Aerobic exercise } \\
\text { (jump rope) }\end{array}$ & Moderate & $5 x /$ wk & 50 & 250 & 12 & $\begin{array}{l}\downarrow \text { WC, } \downarrow \text { SBP, } \downarrow \text { glucose, } \downarrow \text { insulin, } \\
\downarrow \text { HOMA-IR }\end{array}$ \\
\hline $\begin{array}{l}\text { Nascimento } \\
\text { et al. }{ }^{27)}\end{array}$ & $\begin{array}{l}\text { Aerobic exercise } \\
\text { (indoor sports) }\end{array}$ & Low & $3 x / w k$ & 100 & 300 & 8 & $\begin{array}{l}\downarrow \mathrm{BMI}, \downarrow \mathrm{BF} \%, \downarrow \mathrm{CRP}, \downarrow \text { TNF-alpha, } \\
\uparrow \text { adiponectin }\end{array}$ \\
\hline Seabra et al. ${ }^{57)}$ & $\begin{array}{l}\text { Aerobic exercise } \\
\text { (soccer) }\end{array}$ & Moderate & $3 x / w k$ & $60-90$ & $180-270$ & 26 & $\downarrow \mathrm{BF} \%, \downarrow \mathrm{WC}, \downarrow \mathrm{TC}$ \\
\hline Park et al. ${ }^{58)}$ & $\begin{array}{l}\text { Aerobic exercise } \\
\quad \text { (walking) }\end{array}$ & Moderate & $6 x /$ wk & $30-40$ & $180-240$ & 12 & $\downarrow \mathrm{BF} \%, \downarrow \mathrm{BMI}, \downarrow \mathrm{WC}, \downarrow$ waist-hip ratio \\
\hline Kim et al. ${ }^{61)}$ & $\begin{array}{l}\text { Aerobic exercise } \\
\text { (jump rope) }\end{array}$ & Moderate & $5 x /$ wk & 40 & 200 & 6 & $\downarrow$ BF\%, $\uparrow$ insulin sensitivity, $\uparrow$ adiponectin \\
\hline Nassis et al. ${ }^{65)}$ & $\begin{array}{l}\text { Aerobic exercise } \\
\text { (indoor sports) }\end{array}$ & Moderate & $3 x / w k$ & 40 & 120 & 12 & $\begin{array}{l}\uparrow \text { Insulin sensitivity, } \downarrow \text { BF\%, } \downarrow \text { IL-6, } \\
\uparrow \text { adiponectin, } \downarrow \text { CRP }\end{array}$ \\
\hline Sung et al. ${ }^{142)}$ & $\begin{array}{l}\text { Aerobic exercise } \\
\text { (jump rope) }\end{array}$ & Moderate & $5 x / w k$ & 50 & 250 & 12 & $\begin{array}{l}\downarrow \mathrm{BF} \%, \downarrow \text { WC, } \downarrow \text { SBP, } \downarrow \text { baPWV, } \downarrow \text { CRP, } \\
\uparrow \text { nitrate/nitrite levels }\end{array}$ \\
\hline Watts et al. ${ }^{88)}$ & $\begin{array}{l}\text { Aerobic exercise } \\
\text { (cycle ergometer) }\end{array}$ & Moderate & $3 x /$ wk & 60 & 180 & 8 & $\uparrow \mathrm{FMD}$ \\
\hline Racil et al. ${ }^{63)}$ & $\begin{array}{l}\text { Aerobic exercise } \\
\quad(\mathrm{MIIT} / \mathrm{HIIT})\end{array}$ & $\begin{array}{l}\text { Moderate - } \\
\text { High }\end{array}$ & $2 x / w k$ & $12-16$ & $24-32$ & 12 & $\begin{array}{l}\downarrow \mathrm{BMI}, \downarrow \mathrm{BF} \%, \downarrow \mathrm{LDL}, \uparrow \mathrm{HDL}, \\
\uparrow \text { adiponectin, } \downarrow \mathrm{WC}, \downarrow \mathrm{TC}, \downarrow \text { HOMA-IR, } \\
\uparrow \text { insulin sensitivity }\end{array}$ \\
\hline Lee et al. ${ }^{150)}$ & $\begin{array}{l}\text { Aerobic exercise } \\
\text { (treadmill/elliptical) }\end{array}$ & Moderate & $3 x / w k$ & 60 & 180 & 12 & $\begin{array}{l}\downarrow \text { BF\%, } \downarrow \text { intrahepatic lipid, } \\
\uparrow \text { insulin sensitivity }\end{array}$ \\
\hline Lee et al. ${ }^{159)}$ & $\begin{array}{l}\text { Resistance training } \\
\text { (cable machines) }\end{array}$ & Moderate & $3 x / w k$ & 60 & 180 & $\geq 6$ & $\downarrow \mathrm{BF} \%, \downarrow$ insulin resistance \\
\hline Shaibi et al. ${ }^{71)}$ & $\begin{array}{l}\text { Resistance training } \\
\text { (free weights) }\end{array}$ & Moderate & $2 x / w k$ & - & - & 16 & $\begin{array}{l}\downarrow \text { BF\%, } \uparrow \text { insulin sensitivity, } \uparrow \text { adiponectin, } \\
\uparrow \text { upper body strength }\end{array}$ \\
\hline $\begin{array}{l}\text { Van Der Heijden } \\
\text { et al. }{ }^{72)}\end{array}$ & $\begin{array}{l}\text { Resistance training } \\
\text { (free weights) }\end{array}$ & Moderate & $2 x / w k$ & 60 & 120 & 12 & $\begin{array}{l}\uparrow \text { Strength, } \uparrow \text { BW, } \uparrow \text { lean body mass, } \\
\uparrow \text { insulin sensitivity, } \downarrow \text { GPR }\end{array}$ \\
\hline Lee et al. ${ }^{149)}$ & $\begin{array}{l}\text { Resistance training } \\
\text { (whole body training) }\end{array}$ & Moderate & $3 x /$ wk & 60 & 180 & 12 & $\begin{array}{l}\downarrow \text { Visceral fat, } \downarrow \text { intrahepatic lipid, } \uparrow \text { insulin } \\
\text { sensitivity }\end{array}$ \\
\hline Watts et al. ${ }^{89)}$ & $\begin{array}{l}\text { CRAE Training } \\
\text { (RT/Cycling) }\end{array}$ & High & $3 x / w k$ & 60 & 180 & 8 & $\begin{array}{l}\downarrow \text { Abdominal/trunk fat mass, } \uparrow \text { strength, } \\
\uparrow \text { FMD }\end{array}$ \\
\hline Bharath et al. ${ }^{76)}$ & $\begin{array}{c}\text { CRAE training } \\
\text { (resistant band/treadmill) }\end{array}$ & Moderate & $5 x /$ wk & 50 & 250 & 12 & $\begin{array}{l}\downarrow \mathrm{BW}, \downarrow \mathrm{BMI}, \downarrow \text { WC, } \downarrow \text { plasma glucose, } \\
\downarrow \text { insulin, } \downarrow \text { leptin, } \uparrow \text { adiponectin }\end{array}$ \\
\hline Son et al. $^{42)}$ & $\begin{array}{l}\text { CRAE training } \\
\text { (plyometrics/jump rope) }\end{array}$ & Moderate & $3 x / w k$ & 60 & 180 & 12 & $\begin{array}{l}\downarrow \mathrm{BF} \%, \downarrow \text { WC, } \downarrow \mathrm{BP}, \downarrow \text { baPWV }, \downarrow \text { HOMA-IR, } \\
\downarrow \mathrm{ET}-1, \uparrow \text { nitrate/nitrite levels }\end{array}$ \\
\hline Lee et al. ${ }^{159)}$ & $\begin{array}{c}\text { CRAE training } \\
\text { (free weights/running) }\end{array}$ & Moderate & $3 x /$ wk & 60 & 180 & $\geq 6$ & $\downarrow \mathrm{BF} \%, \downarrow \mathrm{BMI}, \downarrow \mathrm{LDL}$ \\
\hline Lopes et al. ${ }^{41)}$ & $\begin{array}{l}\text { CRAE training } \\
\text { (free weights/running) }\end{array}$ & $\begin{array}{l}\text { Moderate - } \\
\text { High }\end{array}$ & $3 x / w k$ & 60 & 180 & 12 & $\begin{array}{l}\downarrow \mathrm{BF} \%, \downarrow \mathrm{CRP}, \downarrow \text { leptin, } \uparrow \text { VOzpeak, } \\
\downarrow \text { insulin resistance, } \uparrow \text { fat-free mass, } \\
\uparrow 1 \mathrm{RM} \text { for leg press }\end{array}$ \\
\hline Wong et al. ${ }^{62)}$ & $\begin{array}{c}\text { CRAE training } \\
\text { (resistant band/treadmill) }\end{array}$ & Moderate & $3 x / w k$ & 50 & 150 & 12 & $\begin{array}{l}\uparrow \text { Nitrate/nitrite levels, } \uparrow \text { adiponectin/leptin } \\
\text { ratio, } \downarrow \text { arterial stiffness, } \downarrow \text { CRP, } \downarrow \text { glucose, } \\
\downarrow \text { insulin, } \downarrow \text { BF\% }\end{array}$ \\
\hline Jeon et al. ${ }^{40)}$ & $\begin{array}{l}\text { CRAE training } \\
\text { (free weights/running) }\end{array}$ & Moderate & $2 x / w k$ & 40 & 80 & 18 & $\begin{array}{l}\downarrow \mathrm{BMI}, \downarrow \mathrm{BF} \%, \downarrow \mathrm{WC}, \downarrow \mathrm{SBP}, \downarrow \mathrm{HOMA}-\mathrm{IR}, \\
\uparrow \text { lean body mass }\end{array}$ \\
\hline Damaso et al. ${ }^{56)}$ & $\begin{array}{c}\text { AE training } \\
\text { (free weights/running) }\end{array}$ & Moderate & $3 x / w k$ & 60 & 180 & 52 & $\downarrow \mathrm{BF} \%, \downarrow \mathrm{LDL}, \uparrow$ lean body mass \\
\hline
\end{tabular}

BMI, body mass index; LDL, low-density lipoprotein; WC, waist circumference; SBP, systolic blood pressure; HOMA-IR, homeostatic model assessment of insulin resistance; $\mathrm{BF} \%$, body fat percentage; CRP, C-reactive protein; baPWV, brachial-to-ankle pulse wave velocity; ET-1, endothelin-1; 1RM, 1 repetition maximum; VO2peak, peak oxygen uptake; TNF-alpha, tumor necrosis factor alpha; IL-6, interleukin 6; TC, total cholesterol; FMD, flowmediated dilation; MIIT/HIIT. moderate-intensity interval training/high-intensity interval training; HDL, high density lipoprotein; BW, body weight; GPR, glucose production rate; CRAE, combined resistance and aerobic exercise; RT, resistance training. 
in childhood or adulthood, may be partially explained by the adverse effect of obesity on the dysregulation of leptin and adiponectin levels which play a crucial role in homeostatic status of IR/sensitivity. ${ }^{38,39)}$ Previous research suggests levels of these adipokines and insulin sensitivity may be positively affected by exercise in obese children and adolescents. ${ }^{27,40-42)}$ Therefore, exercise therapy use in children may support intact homeostatic regulation of leptin and adiponectin levels, which may reduce the likelihood of IR and T2D development in this population.

\section{Leptin}

Leptin's primary function is to promote body mass reduction through sympathetic-driven appetite reduction, ${ }^{43,44)}$ improved lipid metabolism, and increased energy expenditure ${ }^{39)}$ in a healthy, nonobese individual. However, leptin is considered one of the primary hormone markers for obesity. ${ }^{45)}$ Leptin levels are paradoxically increased in obesity, ${ }^{46,47)}$ indicating that obesity is associated with a state of leptin resistance and disturbed leptin bioactivity. Furthermore, increased levels of leptin are strongly correlated with IR and increased inflammation in adolescents ${ }^{48,49)}$ and also contributes to obesity-related hypertension through increased sympathetic tone. ${ }^{43,44)}$

Available literature indicates that exercise interventions have been shown to positively impact leptin levels when there is also a significant decrease in $\mathrm{BF}^{36,50)}$ Many individual studies indicate that $\mathrm{AE}$ interventions improve body composition and leptin levels in obese children and adolescents. ${ }^{51-53)}$ However, previously completed pooled-analyses indicate that there was no signficant affect of AE on leptin levels in obese children and adolescents. ${ }^{36)}$ It is important to note by using nonrandomized control trials, Garcia-Hermoso et al. ${ }^{36}$ ) did conclude that $\mathrm{AE}$ interventions resulted in significantly reduced leptin levels in obese children and adoelscents. To our knowledge, only a single previous study investigates the effects of RT on leptin levels in pediatric obesity. Shultz et al..$^{54)}$ found that following a 16-week RT intervention leptin levels were not significanlty changed in obese adolescents. Interestingly, they did find that participants that had singificantly increased aerobic capacity also had significantly decrease leptin levels following RT. Additionally, Racil et $\mathrm{al}^{55)}$ showed that following 12 weeks of high-intensity interval training (HIIT) there were significant improvements in body composition and reductions in leptin levels in obese adolescents. In the same study, they showed that obese adolescents could gain even greater benefits if they performed CRAE training. Utilizing the same protocol with an additional plyometric component, obese adolescents had significantly greater improvements in body compositions and leptin levels. ${ }^{55)}$ Dâmaso et al. ${ }^{56)}$ also showed that when compared to AE, CRAE training resulted in greater improvements in body composition and leptin levels in obese adolesccents. Overall, previous data show that exercise interventions reduce leptin levels in obese adolescents ${ }^{25}$ and also indicate that the improvements in leptin levels are likely mediated by concomitant reductions in BF due to increased energy expenditure ${ }^{27,41,50,53,57,58)}$ which may be accomplished through exercise interventions of greater frequency, intensity, or duration.

\section{Adiponectin}

Adiponectin is an adipokine with antiatherogenic and antiinflammatory properties ${ }^{59)}$ and is an important regulator of glucose homeostasis and insulin sensitivity ${ }^{38)}$ that helps protect against obesity-related MetS.46) Adiponectin levels are often decreased in obesity. ${ }^{60)}$ However, in pediatric obesity, adiponectin levels may be increased with exercise training, and like leptin, significant improvements in adiponectin levels are strongly associated with decreases in BF and this relationship has been highlighted by many previous exercise training studies with obese adolescents. ${ }^{27,36,61)}$ Dâmaso et al. ${ }^{56}$ ) found that after 1 year of an exercise program consisting of RT and $\mathrm{AE}$ obese adole. scents experienced significant improvements in adiponectin/ leptin ratio and body composition. Additionally, our group has shown that CRAE 3 days per week, for 12 weeks signficantly improved body composition and adiponectin/leptin ratio in obese adolescent girls. ${ }^{62}$ These results are supported by another previous study utilizing CRAE training that observed significant improvements in body composition and adiponection levels in obese adolescents. ${ }^{41)}$ Additionally, the effects of HIIT highlight the relationship between decreased $\mathrm{BF}$ and improved adiponectin levels as Racil et al. ${ }^{63)}$ showed that 12 weeks of moderateintensity interval training (MIIT) and HIIT both improved BF percentage (BF\%), blood lipids, and adiponectin, but HIIT results in significantly greater improvements in these measures in addition to significantly reducing waist circumference (WC). It is important to note that a previous study has shown that combined resistance as CRAE training may positively impact body composition and insulin sensitivity without altering adiponectin levels in obese adolescents. ${ }^{40)}$ In this study, there were no changes in adiponectin levels following a 12 -week exercise program in obese adolescents, however, there were significant improvements in BF, lean body mass, and insulin sensitivity. Similar results have been observed in other studies examining the impacts of $\mathrm{AE}^{64,65)}$ and it was suggested that the improvements in insulin sensitivity were due to improved glucose uptake and utilization by skeletal muscle in response to exercise. ${ }^{66)}$ The exact exerciseinduced mechanisms and training volume and duration implicit in improved adiponectin levels in obese children and adolescents requires further investigation.

\section{Insulin resistance}

T2D is characterized by reduced insulin sensitivity leading to excess blood glucose levels which can contribute to a host of other complications including, CVD, cancer, and diabetic neuropathy, nephropathy, and retinopathy. ${ }^{67)}$ In recent years T2D has increased dramatically in children and adolescents throughout the world ${ }^{68)}$ and there is a strong relationship between the increase in pediatric obesity and rising incidence of T2D. ${ }^{69)}$ It is well established that increased physical activity and exercise are the most comprehensive treatment for the IR associated with 
pediatric obesity. ${ }^{26)}$ IR in pediatric obesity has previously been shown to be improved by a variety of types of exercise including $\mathrm{AE}^{40,70)} \mathrm{RT}^{71,72)} \mathrm{MIIT},{ }^{63)}$ and HIIT. ${ }^{55,63)}$ It is important to note that previous studies have also shown that exercise interventions do not always result in improvements in IR in obese children and adolescents. ${ }^{73,74)} \mathrm{A}$ meta-analysis completed by Marson et al. $^{74)}$ compared the effects of AE, RT, and CRAE training on IR, fasting glucose, and insulin levels in overweight and obese children and adolescents. The analysis concluded that exercise training in general was not associated with a reduction in fasting glucose, however, $\mathrm{AE}$ does result in improvements in fasting insulin levels and IR. Additionally, Marson et al. ${ }^{74)}$ concluded that the efficacy of RT and CRAE training as interventions to improve IR in pediatric obesity could not be determined due to limited available literature. CRAE training is of particular interest as it has been shown to provide greater benefits than $\mathrm{AE}$ or RT alone. ${ }^{75)}$ Our group has shown in multiple studies that CRAE training improves fasting glucose ${ }^{62,70,76)}$ and insulin levels ${ }^{62,70,76)}$ as well as $\mathrm{IR}^{42,70)}$ in obese adolescents. Nonetheless, increasing physical activity in the obese pediatric population is of paramount importance as sedentary behaviors and physical inactivity have been identified as significant contributors to the development of obesity and MetS. ${ }^{14,23,24)}$

\section{Vascular function}

Obesity during adolescence is a well-established marker for increased arterial stiffness, coronary artery calcification, hypertension, and atherosclerosis in adulthood, ${ }^{77)}$ with some atherosclerotic lesions appearing as early as the teenage years. ${ }^{78)} \mathrm{Pe}$. diatric obesity is associated with an increase in a plethora of proatherogenic and proinflammatory factors ${ }^{59,79-86)}$ which contribute to impaired vascular function ${ }^{87-90)}$ and the development of atherosclerosis. ${ }^{91)}$ Obesity-associated IR and leptin resistance as well as increased adipokine secretion promote inflammation and endothelial dysfunction. ${ }^{92-95)}$ Intact endothelial function is widely considered a critical component of a healthy vascular system $^{96}$ and endothelial dysfunction is highly predictive of cardiovascular mortality and morbidity. ${ }^{96-99)}$ Impaired endothelial function has also been identified as an important prerequisite to the development of atherosclerosis ${ }^{96,100)}$ and hypertension. ${ }^{101)}$ Early intervention to prevent atherosclerosis may be essential due to the progressive nature of atherosclerotic development. ${ }^{91)}$ Interventions that enhance vascular function and endothelial function, such as exercise, ${ }^{102-104)}$ may reduce CVD risks for obese children and adolescents as well as protect against cardiovascular mortality and morbidity later in life.

\section{Endothelial function and exercise}

Early intervention to improve vascular function in obese adolescents is of paramount importance, as it may reduce the risk of CVD later in life in through a reduction in global CVD risk. ${ }^{105)}$ Flow-mediated dilation (FMD) is a well-established assessment of vascular endothelial function ${ }^{96)}$ and CVD risk ${ }^{106-}$ 108) in children and adolescents and a decrease in FMD of $1 \%$ results in a $13 \%$ increase in future cardiovascular event risk. ${ }^{97)}$ Previous research has established that pediatric obesity is associated with attenuated vasodilator function through endothelium-dependent mechanisms. ${ }^{88,109,110)}$ Watts et al. ${ }^{88,89)}$ has shown that when compared to lean age-matched control participants, obese adolescent FMD is significantly attenuated, $12.32 \% \pm 3.14 \%$ versus $6.00 \% \pm 0.69 \%,{ }^{88)}$ and $8.9 \% \pm 1.5 \%$ versus $5.3 \% \pm 0.9 \%{ }^{89)}$ Additionally, this group has shown that following exercise training FMD was significantly improved (from $6.00 \% \pm 0.69 \%$ to $7.35 \% \pm 0.99 \%,{ }^{88)}$ from $5.3 \% \pm 0.9 \%$ to $8.8 \% \pm 0.8 \%{ }^{89)}$ ). Dias et al. ${ }^{111)}$ confirmed these results in a 2015 meta-analysis that concluded that obese adolescents had significantly impaired FMD compared to age-matched control participants and that following exercise training the obese adolescent FMD values were restored to the level of the nonobese age-matched counterparts. Furthermore, the effects of exercise training are not specific to the vasculature of the working muscles used during exercise but exercise results in global/systemic improvements in endothelial function. ${ }^{102,104)} \mathrm{It}$ is important to note that endothelial function is often improved following exercise regardless of changes in body composition, BP, or glycemic control ${ }^{89,112)}$ which indicates that the improvements in endothelial function following exercise may be mediated through alterations in hemodynamic factors such as shear stress acting on the vessel wall. ${ }^{113,114)}$ Finally, following periods of detraining the improvements in FMD observed in obese adolescents do not persist. ${ }^{89)}$ These results are in agreement with the loss of endothelial function improvement observed in adults following the cessation of exercise. ${ }^{102,104)}$ This indicates the vascular benefits of exercise are reversible if a physically active lifestyle is not maintained, which therefore supports the incorporation of exercise as a lifestyle change to maintain intact endothelial function. All together the available literature suggests that exercise training is an efficacious therapy to reverse the attenuated endothelial and vascular function associated with pediatric obesity.

\section{Arterial stiffness}

Arterial stiffness indicates vascular compliance and distensibility and is a key player in vascular reactivity and vascular health. ${ }^{115)}$ Pulse wave velocity (PWV) is used as the gold standard measurement for small and larger arterial stiffness, ${ }^{16,117)}$ with increased values corresponding to increased stiffness and decreased compliance and distensibility. ${ }^{118)}$ Considering the relationship between obesity with hypertension and atherosclerosis, it is reasonable to assume that obesity would be associated with increased arterial stiffness which has been shown to be true in obese adults. ${ }^{119)}$ Contradictory to this intuitive conclusion, Charakida et al. ${ }^{120)}$ found that arterial stiffness assessed by PWV was significantly lower in obese adolescents when compared to lean age-matched controls, $6.99 \pm 1.01 \mathrm{~m} / \mathrm{sec}$ and $7.65 \pm 1.23 \mathrm{~m} /$ $\sec (P<0.05)$ respectively, with various other studies confirming 
these results. ${ }^{121-123)}$ The PWV values measured by Charakida etal. in obese adolescents are considered normal and healthy and the difference between groups does not meet the clinically significant threshold of $1.0 \mathrm{~m} / \mathrm{sec}^{124)}$ It is important to note that another group, Cote et al., ${ }^{93)}$ found that obese children and adolescents had significantly greater carotid and aortic PWV values when compared to age-matched nonobese controls. Nonetheless, these results indicate that pediatric obesity may affect vascular structure (stiffness) and function (FMD) differently. The relationship between exercise and arterial stiffness in pediatric obesity is unknown. In adults, measures of arterial stiffness are improved with exercise ${ }^{125)}$ and are significantly lower in adults with greater cardiorespiratory fitness. ${ }^{126)}$ Our group has shown that arterial stiffness was either significantly reduced ${ }^{42,62)}$ or unchanged $^{76}$ in obese adolescents following 12 weeks of CRAE training. However, the reduced arterial stiffness observed was likely due to an improved nitric oxide (NO) and endothelin-1 (ET-1) ratio and increased vasodilatory ${ }^{62)}$ capacity as arterial stiffness is a measurement of a vessel's structural elasticity which tends to change with time. ${ }^{127,128)}$ It is also important to note that in response to exercise previous studies suggest that shear stress, or the force of blood flowing on the endothelial surface, mediates complimentary adaptations in artery function and structure with changes in function preceding changes in structure. ${ }^{114,129)}$ Future research should adopt long-term assessments utilizing multiple time points to determine the vascular adaptations associated with pediatric obesity and the effects of exercise over time on arterial stiffness.

\section{Exercise modality and prescription}

It is widely accepted that obesity is caused by an imbalance between energy intake and energy expenditure, specifically when energy intake exceeds energy expenditure resulting in increased adipose tissue accumulation. Dietary habits, levels of physical activity, and sedentary behaviors all affect an individual's energy balance. ${ }^{130}$ ) Interestingly, modern trends for physical activity reveal that in general, there is a significant increase in the frequency of sedentary behaviors, such as screen time and watching television, during childhood. ${ }^{131)}$ Increased frequency of sedentary behaviors and decreased physical activity time are significant contributors to the development of pediatric obesity as previous research has shown that decreased levels of physical activity are associated with increased $\mathrm{BMI}^{132)}$ and fat mass ${ }^{133)}$ and obesity. ${ }^{14,134)}$ Various obesity-related comorbidities and CVD risk factors can be attributed to the accumulation of excess fat mass. ${ }^{30-32)}$ Previous studies utilizing exercise interventions have shown that exercise improves body composition and has a positive impact on blood lipid profiles and BP as well as blood levels of metabolic hormones in obese children and adolescents (Fig. 1). ${ }^{135,136)}$ However, the effects of exercise may be dependent on the modality of exercise (AE, RT, and CRAE) as each modality may lead to distinct results.

\section{Aerobic exercise}

Obesity is associated with an increased risk of all-cause morbidity and mortality ${ }^{34,137)}$ which can be reduced through improved cardiorespiratory fitness. ${ }^{138)}$ It is well established that in children, adolescents, and adults, $\mathrm{AE}$ is an effective means of improving cardiorespiratory fitness. In fact, $\mathrm{AE}$ training may be the most researched modality of exercise intervention in the pediatric population. $\mathrm{AE}$ is generally performed as a moderateintensity physical exercise such as running, cycling, or jump rope for a sustained period of time, approximately 30-60 minutes per exercise bout, with the purpose of improving the body's ability

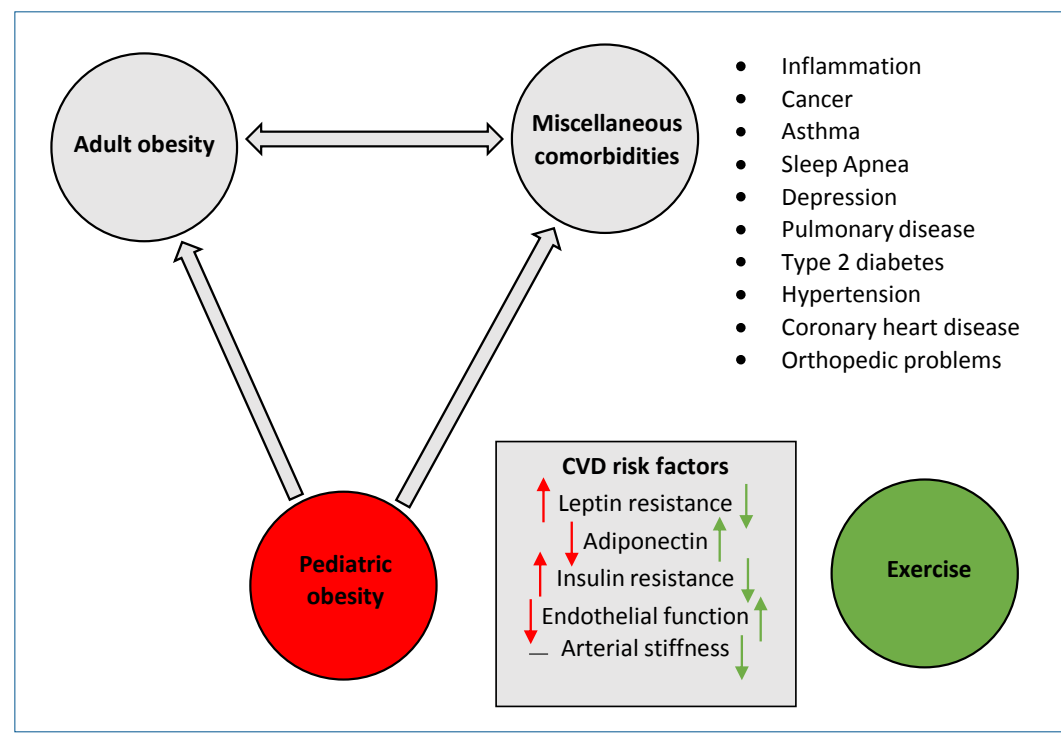

Fig. 1. Obesity is associated with a number of comorbidities as well as increased risk factors for cardiovascular disease. In pediatric obesity, these conditions manifest early in life and have been shown to track into adulthood. Exercise has been shown to be an efficacious therapeutic strategy to combat pediatric obesity. 
to transport and utilize oxygen in the skeletal muscle and the heart. Previous meta-analyses suggest that $\mathrm{AE}$ interventions are effective for reducing fasting insulin levels, IR, ${ }^{74,135)}$ and BF\% ${ }^{139)}$ as well as improving blood lipid levels ${ }^{140)}$ in obese adolescents. Additionally, previous studies have shown that $\mathrm{AE}$ training can lower overall body weight, BMI, low-density lipoprotein, ${ }^{52)}$ as well improve blood levels of leptin, cortisol ${ }^{52)}$ and visfatin. ${ }^{141)}$ Previous studies generally prescribe AE for 30 to 90 minutes at a moderate or moderate-to-vigorous intensity for 3 to 5 days a week. These interventions prescribe progressively more intense $\mathrm{AE}$ over the duration of the interventions which range from 8 weeks to 48 weeks and utilize a variety of modalities including water activities, walking, jogging, and recreational sport. ${ }^{74}$ Our group has previously utilized the same jump rope exercise protocol in 2 separate studies to investigate the effects of exercise on cardiovascular and metabolic parameters in obese adolescents. ${ }^{70,142)}$ The 12-week jump rope exercise program consisted of a 5-minute warm-up, 40 minutes of jump rope which increased in intensity every 4 weeks (weeks $1-4$ at $40 \%-50 \%$ heart rate reserve [HRR], weeks 5-8 at 50\%-60\% HRR, and weeks 9-12 at 60\%-70\% HRR), and a 5-minute cool-down, which was completed 5 days a week for 12 weeks. The 12-week jump rope program resulted in improved body composition, BP, resting levels of NO, ET-1, insulin, and glucose, and reduced markers of inflammation and IR. ${ }^{70,142)} \mathrm{AE}$ is more commonly prescribed to adolescents as AE training modalities such as jump rope, play, dancing, and sport may often be considered more fun and enjoyable which is an important factor for motivation, participation, and long-term adherence. ${ }^{143,144)}$ $\mathrm{AE}$ induces a multitude of positive effects; however, $\mathrm{AE}$ alone may not be the most efficacious exercise modality to combat pediatric obesity.

\section{Resistance training}

RT exercises utilize external loads in the form of free weights, resistance bands, cable machines, or body weight to apply resistance against the contraction of a skeletal muscle with the purpose of increasing muscular strength, power, hypertrophy, and/or endurance. RT is generally performed 1 to 3 times per week while the number of repetitions and sets as well as the duration and intensity of a bout of RT is dependent on the focus of the RT program, muscular strength, power, hypertrophy, or endurance. RT has traditionally been reserved for adult athletes as the primary purpose of RT is to improve muscular performance and it was believed children and adolescents did not experience the same benefits of RT as adults. However, more recent studies suggest that adolescents can improve physical performance, muscle size, and strength through RT. ${ }^{145)}$ Additionally, it is generally accepted that $\mathrm{AE}$ is optimal for reducing BF while RT is optimal for increasing lean body mass. ${ }^{146}$ This may explain why $\mathrm{AE}$ is more commonly prescribed for weight management as reducing fat mass is commonly the primary focus of an exercise prescription for obese individuals due to the negative metabolic and inflammatory effects of excess adipose tissue. ${ }^{33-36)}$ However, AE alone may only minimally affect muscular strength and lean body mass in adults, children, and adolescents. In obese adults, RT has been shown to reduce fat mass and improve blood lipid levels and $\mathrm{IR}^{147,148)}$ but there is limited research focused on investigating the effects of RT on body composition and cardiovascular and metabolic parameters in obese adolescents. Lee et al. ${ }^{149)}$ found that abdominal adiposity was significantly reduced following 3 months of RT or AE in obese adolescent boys but only the RT group's adiposity loss was associated with significant improvements in IR. However, in a follow-up study, the same group found that following 13 weeks of $\mathrm{AE}$ or $\mathrm{RT}, \mathrm{BF} \%$ was significantly reduced in obese adolescent girls but only AE resulted in improved insulin sensitivity which was believed to be attributed to greater reductions in $\mathrm{BF}$ in response to the $\mathrm{AE}$ modality. ${ }^{150)}$ These results indicate that there may be differential responses to RT between sexes in obese adolescents. Previous meta-analyses have identified that RT alone is not associated with significant decreases in fat mass or improvements in metabolic parameters and CVD risk factors in obese children and adolescents. ${ }^{74,151)}$ It was suggested that this may be due to the insufficient literature available and the variations of the study designs and methodologies. In the studies analyzed most prescribed RT interventions were similar to American College of Sports Medicine guidelines (1 to 2 sets of 10 to 15 repetitions of upper body and lower body multi-joint exercises, 2 to 3 times per week) but variance between age, sex, and adherence was present. Even so, current physical activity guidelines for the pediatric population suggest performing $\mathrm{AE}$ and muscle-strengthening activities 3 times per week ${ }^{152)}$ as muscular strength has been shown to be an important factor for protecting against chronic diseases and all-cause mortality. ${ }^{153,154)}$

\section{CRAE training}

As previously discussed, AE and RT interventions may have different effects on body composition and cardiovascular and metabolic parameters in pediatric obesity. CRAE training is a unique training modality that utilizes both AE and RT components in a single exercise protocol to provide the benefits of each modality, which may potentially be more beneficial for metabolic parameters, vascular function, and CVD risk factors than $\mathrm{AE}$ or RT alone. CRAE training generally involves completing a bout of RT, one set of 8-20 repetitions of multiple upper body and lower body resistance exercises, followed by a bout of AE, 20-30 minutes at a moderate intensity, during a single exercise session. CRAE training has been shown to improve both cardiorespiratory fitness and muscular strength $76,155)$ and previous reviews suggest that in adults, CRAE training is more effective for reducing $\mathrm{BF} \%,{ }^{156)} \mathrm{WC}, \mathrm{BP},{ }^{76)}$ levels of blood lipids, and improving glycemic control ${ }^{157)}$ when compared to $\mathrm{AE}$ or RT alone. One CRAE training protocol our group has previously developed consisted of a 5-minute warm-up, 20 minutes of RT (one set of 15-20 repetitions of 5 upper body and 3 lower body exercises), 30 minutes of walking or jogging at 60\%-70\% HRR, and a 5-minute cool-down performed 5 times 
a week for 12 weeks. Our group has shown in obese adolescents that CRAE training improves anthropometric measurements $(\mathrm{BF} \%, \mathrm{WC}){ }^{42,76)}$ reduces BP, arterial stiffness, IR, markers of inflammation, levels of ET-1, and increases NO bioavailability. ${ }^{44)}$ Our findings are supported by previously completed reviews that indicate CRAE training improves body composition, blood lipid profiles, blood levels of adipokines, ${ }^{151,158)}$ and insulin sensitivity. ${ }^{151,159)}$ These reviews also conclude $\mathrm{AE}$ alone and CRAE training are more effective than RT for improving fat mass, lipid profiles, fasting insulin, fasting glucose, and IR but do not provide significantly different benefits. ${ }^{151,159)}$ However, Dâmaso et al. ${ }^{56}$ found that following 1 year of CRAE training obese adolescents experienced significantly greater improvements in BF mass, blood lipid levels, lean body mass, blood levels of leptin and adiponectin, and leptin/adiponectin ratio when compared to obese adolescents that completed 1 year of $\mathrm{AE}$. Further research is required to confirm the efficacy of CRAE training over AE and RT. Nonetheless, it is important that obese children and adolescents perform both $\mathrm{AE}$ and $\mathrm{RT}$, or CRAE training, which is may be more beneficial than $\mathrm{AE}$ or RT alone to prevent the development of obesity-related metabolic diseases and CVD. Additionally, adherence rate of the exercise training is crucial to have positive effects of exercise training for obese children and adolescents. Although there is no study that has directly compared the exercise training adherent rates in $\mathrm{AE}$, $\mathrm{RT}$, and CRAE, our recent studies suggest that CRAE training may have greater exercise training adherence rates compared to AE and RT. Since CRAE training is able to combine multiple different exercise modalities, it may be more enjoyable and less demanding in these young individuals compared to $\mathrm{AE}$ or RT alone. This notion can be supported by previous studies that reported adolescents of various backgrounds have stated that they would be more inclined to engage in exercise if it is perceived as fun and enjoyable. ${ }^{143,144,160)}$ Studies about specific exercise modality, and adherence rate are warranted to develop optimal exercise modalities for pediatric populations.

\section{Conclusion}

Obesity is one of the most prominent public health concerns of modern times with the potential to place a substantial burden on healthcare systems. Pediatric obesity is a well-established risk factor for the development of MetS, T2D, CVD, cancer, and early mortality in adulthood. Although the exact cause of pediatric obesity is multifaceted, it is a condition that can be improved with effective and maintainable lifestyle changes. Exercise has proven to be an efficacious intervention to combat pediatric obesity and its related risk factors and comorbidities. While RT provides benefits, $\mathrm{AE}$ and CRAE training appear to be the most effective exercise modalities to reduce $\mathrm{BF}$ and combat pediatric obesity. Based off of previous research we suggest that the most appropriate exercise prescription to improve pediatric obesity would be a CRAE training protocol, which contains both muscle strengthening (RT) and aerobic components (AE), that places emphasis on reducing fat mass and long-term adherence.

\section{Conflicts of interest}

No potential conflict of interest relevant to this article was reported.

\section{References}

1. Ng M, Fleming T, Robinson M, Thomson B, Graetz N, Margono C, et al. Global, regional, and national prevalence of overweight and obesity in children and adults during 1980-2013: a systematic analysis for the Global Burden of Disease Study 2013. Lancet 2014;384:766-81.

2. GBD 2015 Obesity Collaborators, Afshin A, Forouzanfar MH, Reitsma MB, Sur P, Estep K, et al. Health effects of overweight and obesity in 195 countries over 25 years. NEngl J Med 2017;377:13-27.

3. Gregg EW, Shaw JE. Global health effects of overweight and obesity. N Engl J Med 2017;377:80-1.

4. Ogden CL, Carroll MD, Kit BK, Flegal KM. Prevalence of childhood and adult obesity in the United States, 2011-2012. JAMA 2014;311:806-14.

5. Skinner AC, Skelton JA. Prevalence and trends in obesity and severe obesity among children in the United States, 1999-2012. JAMA Pediatr 2014;168:561-6.

6. Plourde G. Preventing and managing pediatric obesity. Recommendations for family physicians. Can Fam Physician 2006;52:322-8.

7. Han JC, Lawlor DA, Kimm SY. Childhood obesity. Lancet 2010;375: $1737-48$

8. Demir D, Bektas M. The effect of childrens' eating behaviors and parental feeding style on childhood obesity. Eat Behav 2017;26:137-42.

9. Anderson SE, Keim SA. Parent-child interaction, self-regulation, and obesity prevention in early childhood. Curr Obes Rep 2016;5:192-200.

10. Paeratakul S, Ferdinand DP, Champagne CM, Ryan DH, Bray GA. Fastfood consumption among US adults and children: dietary and nutrient intake profile. J Am Diet Assoc 2003;103:1332-8.

11. Ludwig DS, Peterson KE, Gortmaker SL. Relation between consumption of sugar-sweetened drinks and childhood obesity: a prospective, observational analysis. Lancet 2001;357:505-8.

12. Lee EY, Kang B, Yang Y, Yang HK, Kim HS, Lim SY, et al. Study time after school and habitual eating are associated with risk for obesity among overweight korean children: a prospective study. Obes Facts 2018;11:4655.

13. Fisher JO, Birch LL. Eating in the absence of hunger and overweight in girls from 5 to $7 \mathrm{y}$ of age. Am J Clin Nutr 2002;76:226-31.

14. Hernández B, Gortmaker SL, Colditz GA, Peterson KE, Laird NM, Parra-Cabrera S. Association of obesity with physical activity, television programs and other forms of video viewing among children in Mexico city. Int J Obes Relat Metab Disord 1999;23:845-54.

15. Arluk SL, Branch JD, Swain DP, Dowling EA. Childhood obesity's relationship to time spent in sedentary behavior. Mil Med 2003;168:5836.

16. Vicente-Rodríguez G, Rey-López JP, Martín-Matillas M, Moreno LA, Wärnberg J, Redondo C, et al. Television watching, videogames, and excess of body fat in Spanish adolescents: the AVENA study. Nutrition 2008;24:654-62.

17. Andersen RE, Crespo CJ, Bartlett SJ, Cheskin LJ, Pratt M. Relationship of physical activity and television watching with body weight and level of fatness among children: results from the Third National Health and Nutrition Examination Survey. JAMA 1998;279:938-42.

18. Skinner AC, Perrin EM, Moss LA, Skelton JA. Cardiometabolic risks and severity of obesity in children and young adults. N Engl J Med 2015;373:1307-17.

19. Reilly JJ, Kelly J. Long-term impact of overweight and obesity in childhood and adolescence on morbidity and premature mortality in 
adulthood: systematic review. Int J Obes (Lond) 2011;35:891-8.

20. Venn AJ, Thomson RJ, Schmidt MD, Cleland VJ, Curry BA, Gennat HC, et al. Overweight and obesity from childhood to adulthood: a follow-up of participants in the 1985 Australian Schools Health and Fitness Survey. Med J Aust 2007;186:458-60.

21. Simmonds M, Burch J, Llewellyn A, Griffiths C, Yang H, Owen C, et al. The use of measures of obesity in childhood for predicting obesity and the development of obesity-related diseases in adulthood: a systematic review and meta-analysis. Health Technol Assess 2015;19:1-336.

22. Dietz WH. Critical periods in childhood for the development of obesity. Am J Clin Nutr 1994;59:955-9.

23. Thyfault JP, Krogh-Madsen R. Metabolic disruptions induced by reduced ambulatory activity in free-living humans. J Appl Physiol (1985) 2011;111:1218-24.

24. Thyfault JP, Booth FW. Lack of regular physical exercise or too much inactivity. Curr Opin Clin Nutr Metab Care 2011;14:374-8.

25. Sirico F, Bianco A, D'Alicandro G, Castaldo C, Montagnani S, Spera R, et al. Effects of physical exercise on adiponectin, leptin, and inflammatory markers in childhood obesity: systematic review and meta-analysis. Child Obes 2018;14:207-17.

26. Whooten R, Kerem L, Stanley T. Physical activity in adolescents and children and relationship to metabolic health. Curr Opin Endocrinol Diabetes Obes 2019;26:25-31.

27. Nascimento H, Alves AI, Medeiros AF, Coimbra S, Catarino C, Bronzeda-Rocha E, et al. Impact of a school-based intervention protocol ACORDA Project - on adipokines in an overweight and obese pediatric population. Pediatr Exerc Sci 2016;28:407-16.

28. Balagopal P, George D, Yarandi H, Funanage V, Bayne E. Reversal of obesity-related hypoadiponectinemia by lifestyle intervention: a controlled, randomized study in obese adolescents. J Clin Endocrinol Metab 2005;90:6192-7.

29. McMurray RG, Hackney AC. Interactions of metabolic hormones, adipose tissue and exercise. Sports Med 2005;35:393-412.

30. Grundy SM, Cleeman JI, Daniels SR, Donato KA, Eckel RH, Franklin $\mathrm{BA}$, et al. Diagnosis and management of the metabolic syndrome: an American Heart Association/National Heart, Lung, and Blood Institute Scientific Statement. Circulation 2005;112:2735-52.

31. Nicklas TA, von Duvillard SP, Berenson GS. Tracking of serum lipids and lipoproteins from childhood to dyslipidemia in adults: the Bogalusa Heart Study. Int J Sports Med 2002;23 Suppl 1:S39-43.

32. Juhola J, Magnussen CG, Viikari JS, Kähönen M, Hutri-Kähönen N, Jula A, et al. Tracking of serum lipid levels, blood pressure, and body mass index from childhood to adulthood: the Cardiovascular Risk in Young Finns Study. J Pediatr 2011;159:584-90.

33. Ronti T, Lupattelli G, Mannarino E. The endocrine function of adipose tissue: an update. Clin Endocrinol (Oxf) 2006;64:355-65.

34. Kershaw EE, Flier JS. Adipose tissue as an endocrine organ. J Clin Endocrinol Metab 2004;89:2548-56.

35. Havel PJ. Control of energy homeostasis and insulin action by adipocyte hormones: leptin, acylation stimulating protein, and adiponectin. Curr Opin Lipidol 2002;13:51-9.

36. García-Hermoso A, Ceballos-Ceballos RJ, Poblete-Aro CE, Hackney AC, Mota J, Ramírez-Vélez R. Exercise, adipokines and pediatric obesity: a meta-analysis of randomized controlled trials. Int J Obes (Lond) 2017; 41:475-82.

37. Sinha R, Fisch G, Teague B, Tamborlane WV, Banyas B, Allen K, et al. Prevalence of impaired glucose tolerance among children and adolescents with marked obesity. NEngl J Med 2002;346:802-10.

38. Golbidi S, Laher I. Exercise induced adipokine changes and the metabolic syndrome. J Diabetes Res 2014;2014:726861.

39. Ruige JB, Dekker JM, Blum WF, Stehouwer CD, Nijpels G, Mooy J, et al. Leptin and variables of body adiposity, energy balance, and insulin resistance in a population-based study. The Hoorn Study. Diabetes Care 1999;22:1097-104.

40. Jeon JY, Han J, Kim HJ, Park MS, Seo DY, Kwak YS. The combined effects of physical exercise training and detraining on adiponectin in overweight and obese children. Integr Med Res 2013;2:145-50.
41. Lopes WA, Leite N, da Silva LR, Brunelli DT, Gáspari AF, Radominski RB, et al. Effects of 12 weeks of combined training without caloric restriction on inflammatory markers in overweight girls. J Sports Sci 2016;34:190212.

42. Son WM, Sung KD, Bharath LP, Choi KJ, Park SY. Combined exercise training reduces blood pressure, arterial stiffness, and insulin resistance in obese prehypertensive adolescent girls. Clin Exp Hypertens 2017;39: 546-52.

43. Simonds SE, Pryor JT, Ravussin E, Greenway FL, Dileone R, Allen AM, et al. Leptin mediates the increase in blood pressure associated with obesity. Cell 2014;159:1404-16.

44. Trayhurn P, Beattie JH. Physiological role of adipose tissue: white adipose tissue as an endocrine and secretory organ. Proc Nutr Soc 2001;60:32939.

45. Mantzoros CS, Magkos F, Brinkoetter M, Sienkiewicz E, Dardeno TA, Kim SY, et al. Leptin in human physiology and pathophysiology. Am J Physiol Endocrinol Metab 2011;301:E567-84.

46. Ouchi N, Parker JL, Lugus JJ, Walsh K. Adipokines in inflammation and metabolic disease. Nat Rev Immunol 2011;11:85-97.

47. Considine RV, Sinha MK, Heiman ML, Kriauciunas A, Stephens TW, Nyce MR, et al. Serum immunoreactive-leptin concentrations in normalweight and obese humans. NEngl J Med 1996;334:292-5.

48. Li S, Liu R, Arguelles L, Wang G, Zhang J, Shen X, et al. Adiposity trajectory and its associations with plasma adipokine levels in children and adolescents-A prospective cohort study. Obesity (Silver Spring) 2016; 24:408-16.

49. Mantovani RM, Rocha NP, Magalhães DM, Barbosa IG, Teixeira AL, Simões E Silva AC. Early changes in adipokines from overweight to obesity in children and adolescents. J Pediatr (Rio J) 2016;92:624-30.

50. Kelly AS, Steinberger J, Olson TP, Dengel DR. In the absence of weight loss, exercise training does not improve adipokines or oxidative stress in overweight children. Metabolism 2007;56:1005-9.

51. Vasconcellos F, Seabra A, Cunha F, Montenegro R, Penha J, Bouskela E, et al. Health markers in obese adolescents improved by a 12 -week recreational soccer program: a randomised controlled trial. J Sports Sci 2016;34:564-75.

52. Karacabey K. The effect of exercise on leptin, insulin, cortisol and lipid profiles in obese children. J Int Med Res 2009;37:1472-8.

53. Balagopal PB, Gidding SS, Buckloh LM, Yarandi HN, Sylvester JE, George DE, et al. Changes in circulating satiety hormones in obese children: a randomized controlled physical activity-based intervention study. Obesity (Silver Spring) 2010;18:1747-53.

54. Shultz SP, Dahiya R, Leong GM, Rowlands DS, Hills AP, Byrne NM. Muscular strength, aerobic capacity, and adipocytokines in obese youth after resistance training: a pilot study. Australas Med J 2015;8:113-20.

55. Racil G, Zouhal H, Elmontassar W, Ben Abderrahmane A, De Sousa MV, Chamari K, et al. Plyometric exercise combined with high-intensity interval training improves metabolic abnormalities in young obese females more so than interval training alone. Appl Physiol Nutr Metab 2016;41:103-9.

56. Dâmaso AR, da Silveira Campos RM, Caranti DA, de Piano A, Fisberg $\mathrm{M}$, Foschini $\mathrm{D}$, et al. Aerobic plus resistance training was more effective in improving the visceral adiposity, metabolic profile and inflammatory markers than aerobic training in obese adolescents. J Sports Sci 2014;32: 1435-45.

57. Seabra A, Katzmarzyk P, Carvalho MJ, Seabra A, Coelho-E-Silva M, Abreu S, et al. Effects of 6-month soccer and traditional physical activity programmes on body composition, cardiometabolic risk factors, inflammatory, oxidative stress markers and cardiorespiratory fitness in obese boys. J Sports Sci 2016;34:1822-9.

58. Park TG, Hong HR, Lee J, Kang HS. Lifestyle plus exercise intervention improves metabolic syndrome markers without change in adiponectin in obese girls. Ann Nutr Metab 2007;51:197-203.

59. Ouwens DM, Bekaert M, Lapauw B, Van Nieuwenhove Y, Lehr S, Hartwig S, et al. Chemerin as biomarker for insulin sensitivity in males without typical characteristics of metabolic syndrome. Arch Physiol Biochem 2012;118:135-8. 
60. Matsuzawa Y, Funahashi T, Kihara S, Shimomura I. Adiponectin and metabolic syndrome. Arterioscler Thromb Vasc Biol 2004;24:29-33.

61. Kim ES, Im JA, Kim KC, Park JH, Suh SH, Kang ES, et al. Improved insulin sensitivity and adiponectin level after exercise training in obese Korean youth. Obesity (Silver Spring) 2007;15:3023-30.

62. Wong A, Sanchez-Gonzalez MA, Son WM, Kwak YS, Park SY. The effects of a 12-week combined exercise training program on arterial stiffness, vasoactive substances, inflammatory markers, metabolic profile, and body composition in obese adolescent girls. Pediatr Exerc Sci 2018;30:480-6.

63. Racil G, Ben Ounis O, Hammouda O, Kallel A, Zouhal H, Chamari K, et al. Effects of high vs. moderate exercise intensity during interval training on lipids and adiponectin levels in obese young females. Eur J Appl Physiol 2013;113:2531-40.

64. Xydakis AM, Case CC, Jones PH, Hoogeveen RC, Liu MY, Smith EO, et al. Adiponectin, inflammation, and the expression of the metabolic syndrome in obese individuals: the impact of rapid weight loss through caloric restriction. J Clin Endocrinol Metab 2004;89:2697-703.

65. Nassis GP, Papantakou K, Skenderi K, Triandafillopoulou M, Kavouras $\mathrm{SA}$, Yannakoulia $\mathrm{M}$, et al. Aerobic exercise training improves insulin sensitivity without changes in body weight, body fat, adiponectin, and inflammatory markers in overweight and obese girls. Metabolism 2005; 54:1472-9.

66. Roberts CK, Hevener AL, Barnard RJ. Metabolic syndrome and insulin resistance: underlying causes and modification by exercise training. Compr Physiol 2013;3:1-58.

67. Wu Y, Ding Y, Tanaka Y, Zhang W. Risk factors contributing to type 2 diabetes and recent advances in the treatment and prevention. Int J Med Sci 2014;11:1185-200.

68. Chen L, Magliano DJ, Zimmet PZ. The worldwide epidemiology of type 2 diabetes mellitus--present and future perspectives. Nat Rev Endocrinol 2011;8:228-36.

69. Rosenbloom AL, Silverstein JH, Amemiya S, Zeitler P, Klingensmith GJ; International Society for Pediatric, et al. ISPAD clinical practice consensus guidelines 2006-2007. Type 2 diabetes mellitus in the child and adolescent. Pediatr Diabetes 2008;9:512-26.

70. Kim J, Son WM, Headid RJ, Pekas EJ, Noble JM, Park SY. Corrigendum to: the effects of a 12-week jump rope exercise program on body composition, insulin sensitivity, and academic self-efficacy in obese adolescent girls. J Pediatr Endocrinol Metab 2020;33:681.

71. Shaibi GQ, Cruz ML, Ball GD, Weigensberg MJ, Salem GJ, Crespo NC, et al. Effects of resistance training on insulin sensitivity in overweight Latino adolescent males. Med Sci Sports Exerc 2006;38:1208-15.

72. Van Der Heijden GJ, Wang ZJ, Chu Z, Toffolo G, Manesso E, Sauer PJ, et al. Strength exercise improves muscle mass and hepatic insulin sensitivity in obese youth. Med Sci Sports Exerc 2010;42:1973-80.

73. Seo DY, Lee S, Figueroa A, Kim HK, Baek YH, Kwak YS, et al. Yoga training improves metabolic parameters in obese boys. Korean J Physiol Pharmacol 2012;16:175-80.

74. Marson EC, Delevatti RS, Prado AK, Netto N, Kruel LF. Effects of aerobic, resistance, and combined exercise training on insulin resistance markers in overweight or obese children and adolescents: a systematic review and meta-analysis. Prev Med 2016;93:211-8.

75. Ho SS, Dhaliwal SS, Hills AP, Pal S. The effect of 12 weeks of aerobic, resistance or combination exercise training on cardiovascular risk factors in the overweight and obese in a randomized trial. BMC Public Health 2012;12:704.

76. Bharath LP, Choi WW, Cho JM, Skobodzinski AA, Wong A, Sweeney $\mathrm{TE}$, et al. Combined resistance and aerobic exercise training reduces insulin resistance and central adiposity in adolescent girls who are obese: randomized clinical trial. Eur J Appl Physiol 2018;118:1653-60.

77. Chung ST, Onuzuruike AU, Magge SN. Cardiometabolic risk in obese children. Ann NY Acad Sci 2018;1411:166-83.

78. Strong JP, Malcom GT, McMahan CA, Tracy RE, Newman WP 3rd, Herderick EE, et al. Prevalence and extent of atherosclerosis in adolescents and young adults: implications for prevention from the Pathobiological Determinants of Atherosclerosis in Youth Study. JAMA 1999;281:727-35.
79. McGill HC Jr, McMahan CA, Zieske AW, Sloop GD, Walcott JV, Troxclair DA, et al. Associations of coronary heart disease risk factors with the intermediate lesion of atherosclerosis in youth. The Pathobiological Determinants of Atherosclerosis in Youth (PDAY) Research Group. Arterioscler Thromb Vasc Biol 2000;20:1998-2004.

80. Reinehr T, Kiess W, de Sousa G, Stoffel-Wagner B, Wunsch R. Intima media thickness in childhood obesity: relations to inflammatory marker, glucose metabolism, and blood pressure. Metabolism 2006;55:113-8.

81. Zabarsky G, Beek C, Hagman E, Pierpont B, Caprio S, Weiss R. Impact of severe obesity on cardiovascular risk factors in youth. J Pediatr 2018; 192:105-14.

82. Barseghian A, Gawande D, Bajaj M. Adiponectin and vulnerable atherosclerotic plaques. J Am Coll Cardiol 2011;57:761-70.

83. Sabbatini AR, Fontana V, Laurent S, Moreno H. An update on the role of adipokines in arterial stiffness and hypertension. J Hypertens 2015; 33:435-44.

84. Gulcelik NE, Usman A, Gürlek A. Role of adipocytokines in predicting the development of diabetes and its late complications. Endocrine 2009; 36:397-403.

85. McTernan PG, Kusminski CM, Kumar S. Resistin. Curr Opin Lipidol 2006;17:170-5.

86. Daniels SR. Complications of obesity in children and adolescents. Int J Obes (Lond) 2009;33 Suppl 1:S60-5.

87. Hagman E, Danielsson P, Brandt L, Ekbom A, Marcus C. Association between impaired fasting glycaemia in pediatric obesity and type 2 diabetes in young adulthood. Nutr Diabetes 2016;6:e227.

88. Watts K, Beye P, Siafarikas A, O'Driscoll G, Jones TW, Davis EA, et al. Effects of exercise training on vascular function in obese children. $J$ Pediatr 2004;144:620-5.

89. Watts K, Beye P, Siafarikas A, Davis EA, Jones TW, O'Driscoll G, et al. Exercise training normalizes vascular dysfunction and improves central adiposity in obese adolescents. J Am Coll Cardiol 2004;43:1823-7.

90. Mangner N, Scheuermann K, Winzer E, Wagner I, Hoellriegel R, Sandri $\mathrm{M}$, et al. Childhood obesity: impact on cardiac geometry and function. JACC Cardiovasc Imaging 2014;7:1198-205.

91. Gimbrone MA Jr, García-Cardeña G. Endothelial Cell Dysfunction and the Pathobiology of Atherosclerosis. Circ Res 2016;118:620-36.

92. TODAY Study Group. Lipid and inflammatory cardiovascular risk worsens over 3 years in youth with type 2 diabetes: the TODAY clinical trial. Diabetes Care 2013;36:1758-64.

93. Cote AT, Phillips AA, Harris KC, Sandor GG, Panagiotopoulos C, Devlin AM. Obesity and arterial stiffness in children: systematic review and meta-analysis. Arterioscler Thromb Vasc Biol 2015;35:1038-44.

94. Northcott JM, Yeganeh A, Taylor CG, Zahradka P, Wigle JT. Adipokines and the cardiovascular system: mechanisms mediating health and disease. Can J Physiol Pharmacol 2012;90:1029-59.

95. Chen C, Jiang J, Lü JM, Chai H, Wang X, Lin PH, et al. Resistin decreases expression of endothelial nitric oxide synthase through oxidative stress in human coronary artery endothelial cells. Am J Physiol Heart Circ Physiol 2010;299:H193-201.

96. Vita JA, Keaney JF Jr. Endothelial function: a barometer for cardiovascular risk? Circulation 2002;106:640-2.

97. Inaba Y, Chen JA, Bergmann SR. Prediction of future cardiovascular outcomes by flow-mediated vasodilatation of brachial artery: a metaanalysis. Int J Cardiovasc Imaging 2010;26:631-40.

98. Green DJ, Jones H, Thijssen D, Cable NT, Atkinson G. Flow-mediated dilation and cardiovascular event prediction: does nitric oxide matter? Hypertension 2011;57:363-9.

99. Ras RT, Streppel MT, Draijer R, Zock PL. Flow-mediated dilation and cardiovascular risk prediction: a systematic review with meta-analysis. Int J Cardiol 2013;168:344-51.

100. Okumura K, Imamura A, Murakami R, Numaguchi Y, Matsui H, Toyoaki M. Endothelial function and early atherosclerotic changes. Future Cardiol 2005;1:501-8.

101. Higashi Y, Kihara Y, Noma K. Endothelial dysfunction and hypertension in aging. Hypertens Res 2012;35:1039-47.

102. Maiorana A, O'Driscoll G, Dembo L, Cheetham C, Goodman C, Taylor 
$\mathrm{R}$, et al. Effect of aerobic and resistance exercise training on vascular function in heart failure. Am J Physiol Heart Circ Physiol 2000;279: H1999-2005.

103. Hambrecht R, Wolf A, Gielen S, Linke A, Hofer J, Erbs S, et al. Effect of exercise on coronary endothelial function in patients with coronary artery disease. NEngl J Med 2000;342:454-60.

104. Maiorana A, O'Driscoll G, Cheetham C, Dembo L, Stanton K, Goodman $\mathrm{C}$, et al. The effect of combined aerobic and resistance exercise training on vascular function in type 2 diabetes. J Am Coll Cardiol 2001; 38:860-6

105. Versari D, Daghini E, Virdis A, Ghiadoni L, Taddei S. Endothelial dysfunction as a target for prevention of cardiovascular disease. Diabetes Care 2009;32 Suppl 2(Suppl 2):S314-21.

106. Celermajer DS, Sorensen KE, Georgakopoulos D, Bull C, Thomas O, Robinson J, et al. Cigarette smoking is associated with dose-related and potentially reversible impairment of endothelium-dependent dilation in healthy young adults. Circulation 1993;88(5 Pt 1):2149-55.

107. Celermajer DS, Sorensen K, Ryalls M, Robinson J, Thomas O, Leonard $\mathrm{JV}$, et al. Impaired endothelial function occurs in the systemic arteries of children with homozygous homocystinuria but not in their heterozygous parents. J Am Coll Cardiol 1993;22:854-8.

108. Sorensen KE, Celermajer DS, Georgakopoulos D, Hatcher G, Betteridge DJ, Deanfield JE. Impairment of endothelium-dependent dilation is an early event in children with familial hypercholesterolemia and is related to the lipoprotein(a) level. J Clin Invest 1994;93:50-5.

109. Tounian P, Aggoun Y, Dubern B, Varille V, Guy-Grand B, Sidi D, et al. Presence of increased stiffness of the common carotid artery and endothelial dysfunction in severely obese children: a prospective study. Lancet 2001;358:1400-4.

110. Farpour-Lambert NJ, Aggoun Y, Marchand LM, Martin XE, Herrmann FR, Beghetti M. Physical activity reduces systemic blood pressure and improves early markers of atherosclerosis in pre-pubertal obese children. J Am Coll Cardiol 2009;54:2396-406.

111. Dias KA, Green DJ, Ingul CB, Pavey TG, Coombes JS. Exercise and vascular function in child obesity: a meta-analysis. Pediatrics 2015;136: e648-59.

112. Green DJ, Walsh JH, Maiorana A, Best MJ, Taylor RR, O'Driscoll JG. Exercise-induced improvement in endothelial dysfunction is not mediated by changes in CV risk factors: pooled analysis of diverse patient populations. Am J Physiol Heart Circ Physiol 2003;285:H267987.

113. Niebauer J, Cooke JP. Cardiovascular effects of exercise: role of endothelial shear stress. J Am Coll Cardiol 1996;28:1652-60.

114. Tinken TM, Thijssen DH, Hopkins N, Dawson EA, Cable NT, Green DJ. Shear stress mediates endothelial adaptations to exercise training in humans. Hypertension 2010;55:312-8.

115. Cecelja M, Chowienczyk P. Role of arterial stiffness in cardiovascular disease. JRSM Cardiovasc Dis 2012;1:cvd.2012.012016.

116. Yamashina A, Tomiyama H, Takeda K, Tsuda H, Arai T, Hirose K, et al. Validity, reproducibility, and clinical significance of noninvasive brachialankle pulse wave velocity measurement. Hypertens Res 2002;25:35964.

117. Laurent S, Cockcroft J, Van Bortel L, Boutouyrie P, Giannattasio C, Hayoz D, et al. Expert consensus document on arterial stiffness: methodological issues and clinical applications. Eur Heart J 2006;27:2588605.

118. Pereira T, Correia C, Cardoso J. Novel methods for pulse wave velocity measurement. J Med Biol Eng 2015;35:555-65.

119. Acree LS, Montgomery PS, Gardner AW. The influence of obesity on arterial compliance in adult men and women. Vasc Med 2007;12:183-8.

120. Charakida M, Jones A, Falaschetti E, Khan T, Finer N, Sattar N, et al. Childhood obesity and vascular phenotypes: a population study. J Am Coll Cardiol 2012;60:2643-50.

121. Czippelova B, Turianikova Z, Krohova J, Wiszt R, Lazarova Z, Pozorciakova $\mathrm{K}$, et al. Arterial stiffness and endothelial function in young obese patients - vascular resistance matters. J Atheroscler Thromb 2019;26:1015-25.
122. Mestanik M, Jurko A, Spronck B, Avolio AP, Butlin M, Jurko T, et al. Improved assessment of arterial stiffness using corrected cardio-ankle vascular index (CAVI0) in overweight adolescents with white-coat and essential hypertension. Scand J Clin Lab Invest 2017;77:665-72.

123. Nagayama D, Imamura H, Sato Y, Yamaguchi T, Ban N, Kawana H, et al. Inverse relationship of cardioankle vascular index with BMI in healthy Japanese subjects: a cross-sectional study. Vasc Health Risk Manag 2016; 13:1-9.

124. Vlachopoulos C, Aznaouridis K, Stefanadis C. Prediction of cardiovascular events and all-cause mortality with arterial stiffness: a systematic review and meta-analysis. J Am Coll Cardiol 2010;55:1318-27.

125. Ashor AW, Lara J, Siervo M, Celis-Morales C, Mathers JC. Effects of exercise modalities on arterial stiffness and wave reflection: a systematic review and meta-analysis of randomized controlled trials. PLoS One 2014;9:e110034.

126. Santos-Parker JR, LaRocca TJ, Seals DR. Aerobic exercise and other healthy lifestyle factors that influence vascular aging. Adv Physiol Educ 2014;38:296-307.

127. Lee HY, Oh BH. Aging and arterial stiffness. Circ J 2010;74:2257-62.

128. Cavalcante JL, Lima JA, Redheuil A, Al-Mallah MH. Aortic stiffness: current understanding and future directions. J Am Coll Cardiol 2011; 57:1511-22.

129. Tinken TM, Thijssen DH, Black MA, Cable NT, Green DJ. Time course of change in vasodilator function and capacity in response to exercise training in humans. J Physiol 2008;586:5003-12.

130. Davison KK, Birch LL. Childhood overweight: a contextual model and recommendations for future research. Obes Rev 2001;2:159-71.

131. Anderson PM, Butcher KE. Childhood obesity: trends and potential causes. Future Child 2006;16:19-45.

132. Obarzanek E, Schreiber GB, Crawford PB, Goldman SR, Barrier PM, Frederick MM, et al. Energy intake and physical activity in relation to indexes of body fat: the National Heart, Lung, and Blood Institute Growth and Health Study. Am J Clin Nutr 1994;60:15-22.

133. Goran MI, Hunter G, Nagy TR, Johnson R. Physical activity related energy expenditure and fat mass in young children. Int J Obes Relat Metab Disord 1997;21:171-8.

134. Fogelholm M, Nuutinen O, Pasanen M, Myöhänen E, Säätelä T. Parentchild relationship of physical activity patterns and obesity. Int J Obes Relat Metab Disord 1999;23:1262-8.

135. García-Hermoso A, Saavedra JM, Escalante Y, Sánchez-López M, Martínez-Vizcaíno V. Endocrinology and Adolescence: aerobic exercise reduces insulin resistance markers in obese youth: a meta-analysis of randomized controlled trials. Eur J Endocrinol 2014;171:R163-71.

136. Jamurtas AZ, Stavropoulos-Kalinoglou A, Koutsias S, Koutedakis Y, Fatouros I. Adiponectin, resistin, and visfatin in childhood obesity and exercise. Pediatr Exerc Sci 2015;27:454-62.

137. Twig G, Yaniv G, Levine H, Leiba A, Goldberger N, Derazne E, et al. Body-mass index in 2.3 million adolescents and cardiovascular death in adulthood. NEngl J Med 2016;374:2430-40.

138. Barry VW, Baruth M, Beets MW, Durstine JL, Liu J, Blair SN. Fitness vs. fatness on all-cause mortality: a meta-analysis. Prog Cardiovasc Dis 2014;56:382-90.

139. Kelley GA, Kelley KS. Effects of aerobic exercise on non-high-density lipoprotein cholesterol in children and adolescents: a meta-analysis of randomized controlled trials. Prog Cardiovasc Nurs 2008;23:128-32.

140. Kelley GA, Kelley KS. Aerobic exercise and lipids and lipoproteins in children and adolescents: a meta-analysis of randomized controlled trials. Atherosclerosis 2007;191:447-53.

141. Lee KJ, Shin YA, Lee KY, Jun TW, Song W. Aerobic exercise traininginduced decrease in plasma visfatin and insulin resistance in obese female adolescents. Int J Sport Nutr Exerc Metab 2010;20:275-81.

142. Sung KD, Pekas EJ, Scott SD, Son WM, Park SY. Correction to: the effects of a 12-week jump rope exercise program on abdominal adiposity, vasoactive substances, inflammation, and vascular function in adolescent girls with prehypertension. Eur J Appl Physiol 2020;120:1203.

143. Taylor WC, Yancey AK, Leslie J, Murray NG, Cummings SS, Sharkey SA, et al. Physical activity among African American and Latino middle 
school girls: consistent beliefs, expectations, and experiences across two sites. Women Health 1999;30:67-82.

144. Robbins LB, Pender NJ, Kazanis AS. Barriers to physical activity perceived by adolescent girls. J Midwifery Womens Health 2003;48:206-12.

145. Matos N, Winsley RJ. Trainability of young athletes and overtraining. J Sports Sci Med 2007;6:353-67.

146. Willis LH, Slentz CA, Bateman LA, Shields AT, Piner LW, Bales CW, et al. Effects of aerobic and/or resistance training on body mass and fat mass in overweight or obese adults. J Appl Physiol (1985) 2012;113:1831-7.

147. Westcott WL. Resistance training is medicine: effects of strength training on health. Curr Sports Med Rep 2012;11:209-16.

148. Di Meo S, Iossa S, Venditti P. Improvement of obesity-linked skeletal muscle insulin resistance by strength and endurance training. J Endocrinol 2017;234:R159-81.

149. Lee S, Bacha F, Hannon T, Kuk JL, Boesch C, Arslanian S. Effects of aerobic versus resistance exercise without caloric restriction on abdominal fat, intrahepatic lipid, and insulin sensitivity in obese adolescent boys: a randomized, controlled trial. Diabetes 2012;61:2787-95.

150. Lee S, Deldin AR, White D, Kim Y, Libman I, Rivera-Vega M, et al. Aerobic exercise but not resistance exercise reduces intrahepatic lipid content and visceral fat and improves insulin sensitivity in obese adolescent girls: a randomized controlled trial. Am J Physiol Endocrinol Metab 2013;305:E1222-9.

151. Lee S, Kim Y, Kuk JL. What is the role of resistance exercise in improving the cardiometabolic health of adolescents with obesity? J Obes Metab Syndr 2019;28:76-91.

152. Piercy KL, Troiano RP, Ballard RM, Carlson SA, Fulton JE, Galuska DA, et al. The physical activity guidelines for Americans. JAMA 2018; 320:2020-8

153. Ruiz JR, Sui X, Lobelo F, Morrow JR Jr, Jackson AW, Sjöström M, et al. Association between muscular strength and mortality in men: prospective cohort study. BMJ 2008;337:a439.
154. Ruiz JR, Sui X, Lobelo F, Lee DC, Morrow JR Jr, Jackson AW, et al Muscular strength and adiposity as predictors of adulthood cancer mortality in men. Cancer Epidemiol Biomarkers Prev 2009;18:146876.

155. Santos AP, Marinho DA, Costa AM, Izquierdo M, Marques MC. The effects of concurrent resistance and endurance training follow a detraining period in elementary school students. J Strength Cond Res 2012;26:1708-16.

156. Schwingshackl L, Dias S, Strasser B, Hoffmann G. Impact of different training modalities on anthropometric and metabolic characteristics in overweight/obese subjects: a systematic review and network metaanalysis. PLoS One 2013;8:e82853.

157. Schwingshackl L, Missbach B, Dias S, König J, Hoffmann G. Impact of different training modalities on glycaemic control and blood lipids in patients with type 2 diabetes: a systematic review and network metaanalysis. Diabetologia 2014;57:1789-97.

158. García-Hermoso A, Ramírez-Vélez R, Ramírez-Campillo R, Peterson MD, Martínez-Vizcaíno V. Concurrent aerobic plus resistance exercise versus aerobic exercise alone to improve health outcomes in paediatric obesity: a systematic review and meta-analysis. Br J Sports Med 2018; 52:161-6.

159. Lee S, Libman I, Hughan K, Kuk JL, Jeong JH, Zhang D, et al. Effects of exercise modality on insulin resistance and ectopic fat in adolescents with overweight and obesity: a randomized clinical trial. J Pediatr 2019;206:91-8.e1.

160. Galan-Lopez P, Ries F. Motives for exercising and associations with body composition in icelandic adolescents. Sports (Basel) 2019;7:149.

How to cite this article: Headid RJ, Park SY. The impacts of exercise on pediatric obesity. Clin Exp Pediatr 2021;64:196-207. https://doi.org/10.3345/cep.2020.00997 